Article

\title{
Preparation, Sinterability, Electrical Transport and Thermal Expansion of Perovskite-Type $\mathrm{La}_{0.8} \mathrm{Ca}_{0.2} \mathrm{CrO}_{3}$ Composites
}

\author{
Linlin Liu ${ }^{1}$, Mingmei Jiang ${ }^{1, *}$, Juanjuan Yin ${ }^{2}$, Wenfeng Guo ${ }^{2}$ and Tifeng Jiao ${ }^{2, * \mathbb{D}}$ \\ 1 Qinhuangdao Campus, Northeast Petroleum University, Qinhuangdao 066004, China; liulinlin@nepu.edu.cn \\ 2 State Key Laboratory of Metastable Materials Science and Technology, Yanshan University, \\ Qinhuangdao 066004, China; jjyin@stumail.ysu.edu.cn (J.Y.); wfguo@ysu.edu.cn (W.G.) \\ * Correspondence: mingmeij@nepu.edu.cn (M.J.); tfjiao@ysu.edu.cn (T.J.); Tel.: +86-335-805-6854 (T.J.)
}

Received: 13 June 2020; Accepted: 2 July 2020; Published: 4 July 2020

check for updates

\begin{abstract}
Perovskite-type was synthesized by two methods, the combustion method and conventional solid state reaction (SSR) method. The effect of synthesis methods on sinterability and physical properties of the ceramic were investigated. The results show that there are advantages of the combustion method in producing doped lanthanum chromites. Compared with the SSR method, the combustion method reduces the sintering temperature of $\mathrm{La}_{0.8} \mathrm{Ca}_{0.2} \mathrm{CrO}_{3}$, elevates the electronic conductivity and thermal expansion coefficient (TEC) of the ceramic, due to optimizing the microstructure. At the same densities level $(-93 \%)$, the specimen synthesized by the combustion method reaches a superior electrical conductivity of $31.6 \mathrm{~S} \cdot \mathrm{cm}^{-1}$ and a compatible TEC of $10.7 \times 10^{-6} \mathrm{~K}^{-1}$ at $800{ }^{\circ} \mathrm{C}$.
\end{abstract}

Keywords: perovskite-type $\mathrm{La}_{0.8} \mathrm{Ca}_{0.2} \mathrm{CrO}_{3}$; combustion method; microstructure; electrical conductivity; thermal expansion coefficient (TEC)

\section{Introduction}

Lanthanum chromite $\left(\mathrm{LaCrO}_{3}\right)$-based perovskite phases possess high melting points, large electronic conductivity and stability in high-temperature reducing and oxidizing atmospheres, which makes them promising candidates for heating elements of muffle furnaces and current-conducting electrodes in magneto-hydrodynamics, especially interconnectors of solid oxide fuel cell (SOFCs) [1-6]. The interconnections of SOFCs have a dual function of separating reducing and oxidizing gases and providing a short-circuit current between individual cells. Therefore, the interconnection of SOFCs must be tight. Nevertheless, $\mathrm{LaCrO}_{3}$ is difficult to sinter to high densities in air, due to appreciable volatilization loss of chromium oxide at high temperatures in oxidizing atmospheres [7-9]. Therefore, a considerable amount of research effort has been performed on improving the sintering properties of the ceramic materials [6-12], and the results have been demonstrated the advantage of alkaline earth metal $(\mathrm{AE}=\mathrm{Ca}, \mathrm{Sr})$ substituted $\mathrm{LaCrO}_{3}$, due to a transient liquid phase (e.g., $\mathrm{CaCrO}_{4}$ and $\mathrm{SrCrO}_{4}$ ) formed in the early stage of sintering and suppressing the vaporization of $\mathrm{Cr}-\mathrm{O}$ species to some extent [10-12]. However, the application of excess AE substituted $\mathrm{LaCrO}_{3}$ may lead to the long-term operation stability of the system $[13,14]$.

It is well known that the sinterability of the ceramics could be enhanced by highly reactive powders synthesized by wet chemical methods. Moreover, physical properties of the ceramics, such as electrical transport and thermal expansion, may be affected by the characteristics of the powders synthesized by the methods, possibly due to different microstructures of the sintered ceramics. In this work, we synthesized $\mathrm{La}_{0.8} \mathrm{Ca}_{0.2} \mathrm{CrO}_{3}$ powders by a combustion method in comparison with the high temperature solid state reaction (SSR) method, and investigated the influence of preparation methods on sinterability, electrical transport and thermal expansion of the ceramics. 


\section{Materials and Methods}

\subsection{Materials}

All chemical reagents were of AR grades and were purchased from Shanghai Chemical Reagent Factory of China without further purification. Distilled water was used in all solutions. $\mathrm{La}_{0.8} \mathrm{Ca}_{0.2} \mathrm{CrO}_{3}$ powder was synthesized by a combustion method, using metal nitrates as oxidizers and glycine as a fuel. Reagent grade $\mathrm{La}\left(\mathrm{NO}_{3}\right)_{3} \cdot 6 \mathrm{H}_{2} \mathrm{O}, \mathrm{Ca}\left(\mathrm{NO}_{3}\right)_{2} \cdot 4 \mathrm{H}_{2} \mathrm{O}, \mathrm{Cr}\left(\mathrm{NO}_{3}\right)_{3} \cdot 9 \mathrm{H}_{2} \mathrm{O}$ and glycine were used as starting materials. Moreover, the details of the technique of the combustion method for obtaining $\mathrm{La}_{0.8} \mathrm{Ca}_{0.2} \mathrm{CrO}_{3}$ powders of submicron size particles have been described elsewhere $[15,16]$. The resultant powders were pressed into rectangular bars $\left(30 \times 4 \times 4 \mathrm{~mm}^{3}\right)$, and then sintered at $1200-1450{ }^{\circ} \mathrm{C}$ for $4 \mathrm{~h}$ in air. In addition, $\mathrm{La}_{0.8} \mathrm{Ca}_{0.2} \mathrm{CrO}_{3}$ was also synthesized by the high temperature SSR method using $\mathrm{La}_{2} \mathrm{O}_{3}$, $\mathrm{Cr}_{2} \mathrm{O}_{3}$ and $\mathrm{CaO}$ as raw materials. Then the specimen sintered at $1300-1550{ }^{\circ} \mathrm{C}$ for $4 \mathrm{~h}$ in air.

\subsection{Characterization}

The crystalline structure of the synthesized powders was investigated by an X-ray diffractometer equipped with a $\mathrm{Cu} \mathrm{K} \alpha$ X-ray radiation source and a Bragg diffraction setup (SMART LAB, Rigaku, Tokyo, Japan). The morphology of the synthesized powders and the fractured cross sections of sintered specimens etched in diluted hybrid acids were characterized by a scanning electron microscope (SEM, Hitachi S-4800-II, JEOL Ltd., Tokyo, Japan). Relative densities of the sintered ceramics were determined from the apparent density values measured by the Archimedes method and the theoretical density calculated from the lattice parameter of the solid solution. The ceramic specimens were polished to ensure surface flatness and painted with platinum paste for measuring electrical conductivity. The electrical conductivity was then measured at $25^{\circ} \mathrm{C}-800^{\circ} \mathrm{C}$ by a direct current four-terminal method in air. Thermal expansion of the polished bars specimens was tested using a dilatometer (NETZSCH DIL402C, NETZSCH, Selb, Germany) with a heating rate of $5^{\circ} \mathrm{C} \cdot \mathrm{min}^{-1}$ from $25^{\circ} \mathrm{C}$ to $800{ }^{\circ} \mathrm{C}$ in air.

\section{Results}

\subsection{XRD and SEM of the $\mathrm{La}_{0.8} \mathrm{Ca}_{0.2} \mathrm{CrO}_{3}$ Powders}

XRD patterns of $\mathrm{La}_{0.8} \mathrm{Ca}_{0.2} \mathrm{CrO}_{3}$ powders are shown in Figure 1a. The samples were synthesized by both combustion and SSR methods. It can be seen that an almost single perovskite phase was obtained for the powders by the combustion method. However, the sample by the SSR method displayed a stronger intensity of a perovskite phase with a little amount of $\mathrm{CaCrO}_{4}$ and $\mathrm{Cr}_{2} \mathrm{O}_{3}$. The stronger diffraction peaks of the perovskite may have been due to a higher synthesis temperature. Moreover, a slight amount of $\mathrm{CaCrO}_{4}$ as a second phase could redissolve the perovskite matrix above $100{ }^{\circ} \mathrm{C}$ and $\mathrm{Cr}_{2} \mathrm{O}_{3}$ was considered as incomplete reaction impurity substance. Figure $1 \mathrm{~b}, \mathrm{c}$ shows the SEM micrographs of $\mathrm{La}_{0.8} \mathrm{Ca}_{0.2} \mathrm{CrO}_{3}$ powders synthesized by the two methods. The powder by the combustion method consisted of homogeneous, fine submicron particles $(0.1-0.2 \mu \mathrm{m})$ estimated from the SEM micrographs.

The above results exhibit the advantage of the combustion method in synthesizing $\mathrm{La}_{0.8} \mathrm{Ca}_{0.2} \mathrm{CrO}_{3}$ powders. It may be ascribed to that the combustion method could complex metal ions by means of the organic agent and release a relatively large volume of heat and gases, matching a number of the particular characteristics such as high purity, high surface area and hard agglomerate-free [10,17]. All the advantages could help the $\mathrm{La}_{0.8} \mathrm{Ca}_{0.2} \mathrm{CrO}_{3}$ ceramics possess superior sinterability and physical properties. 

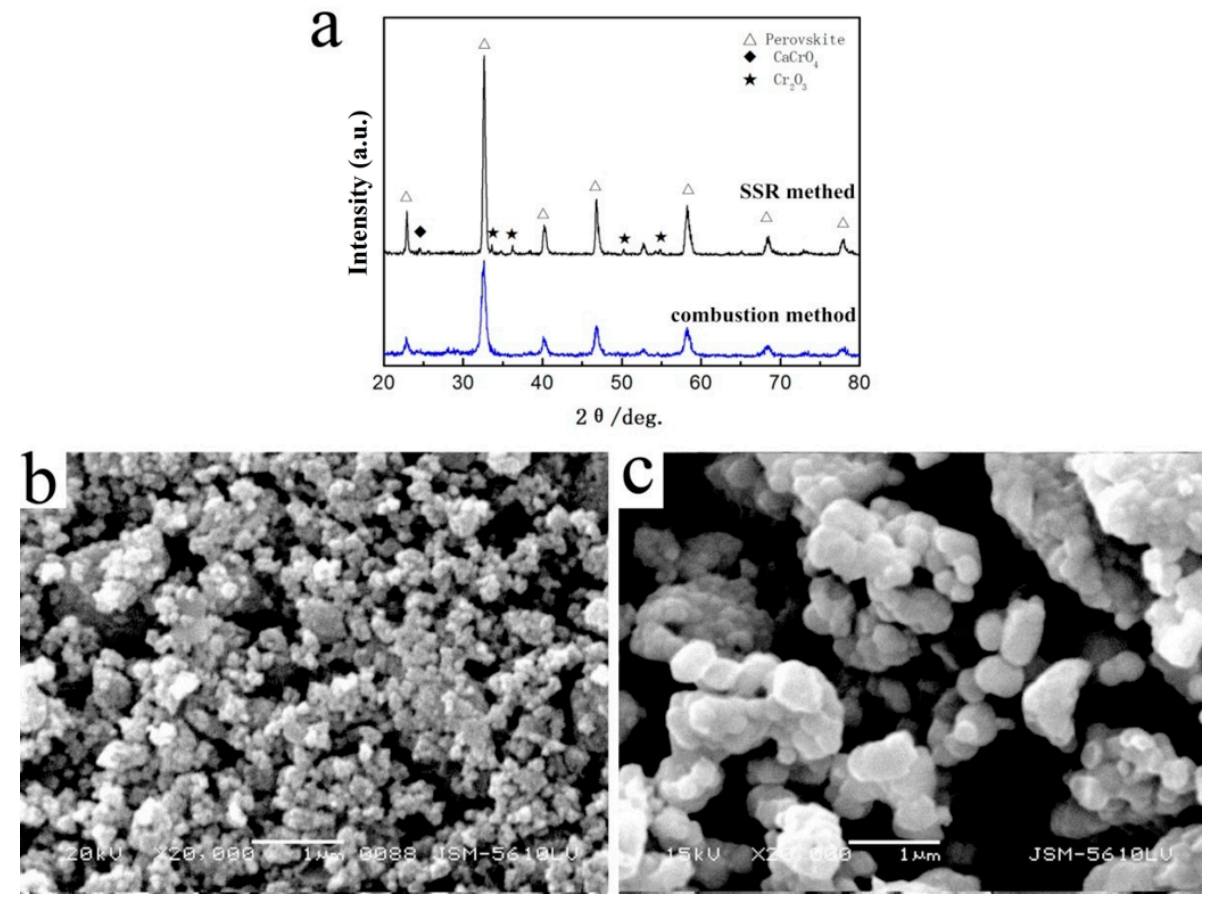

Figure 1. (a) XRD patterns and SEM images of $\mathrm{La}_{0.8} \mathrm{Ca}_{0.2} \mathrm{CrO}_{3}$ powders synthesized by (b) the combustion method and (c) the conventional solid state reaction (SSR) method, respectively.

\subsection{Sintering Characterization}

Figure 2 shows the relative densities of $\mathrm{La}_{0.8} \mathrm{Ca}_{0.2} \mathrm{CrO}_{3}$ ceramics synthesized by the two different methods, as a function of sintering temperature. It is clear from the above figure that at approximately $1400{ }^{\circ} \mathrm{C}$, a higher relative density value of $93 \%$ was obtained for the combustion method samples, whereas in the case of the sample synthesized by the SSR method, the densification started at the same temperature and a relative density value of $90 \%$ was not achieved until $1500{ }^{\circ} \mathrm{C}$. In contrast, the $\mathrm{La}_{0.8} \mathrm{Ca}_{0.2} \mathrm{CrO}_{3}$ powders synthesized by the combustion exhibit better sinterability, due to finer particle morphology and high sintering activity. The above-mentioned results were also supported by the microstructural variations observed on the sintered samples.

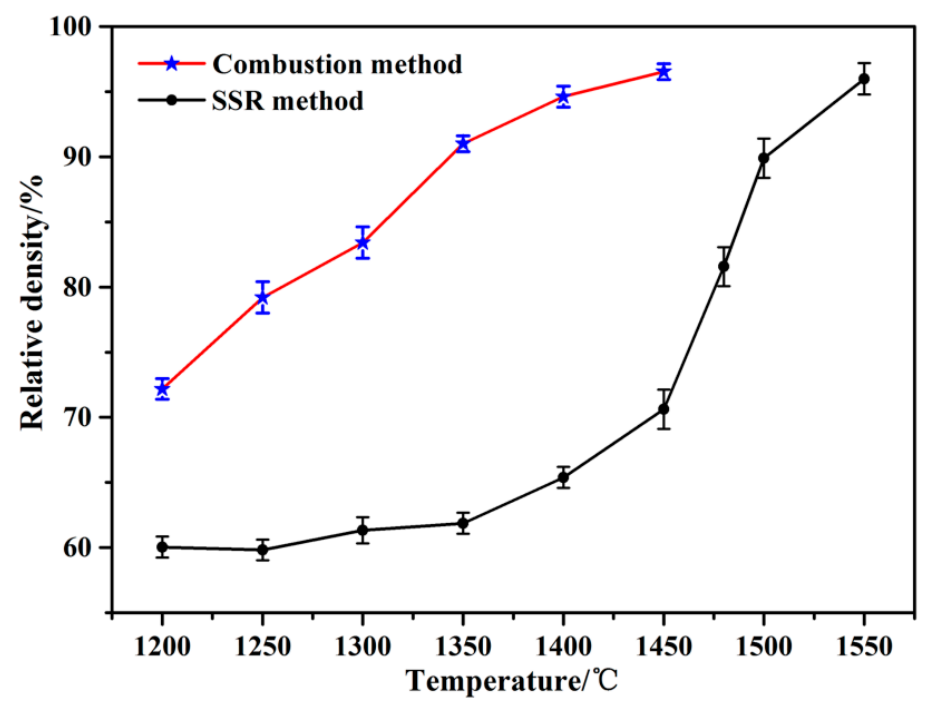

Figure 2. Relative densities of $\mathrm{La}_{0.8} \mathrm{Ca}_{0.2} \mathrm{CrO}_{3}$ ceramics synthesized by the two methods. 
Figure 3 shows SEM micrographs of fracture surfaces of $\mathrm{La}_{0.8} \mathrm{Ca}_{0.2} \mathrm{CrO}_{3}$ ceramics synthesized by the combustion and SSR methods as a function of the sintering temperature. It can be seen that a close-grained microstructure was obtained for the combustion method sample sintered at $1400{ }^{\circ} \mathrm{C}$ in Figure 3a. While the SSR sample sintered at the same temperature displayed a porous microstructure with small grain size in Figure 3b. Despite the compact microstructure, Figure 3c showed many small holes on the surface of grains of the ceramics made by the high temperature SSR method and sintered at $1500^{\circ} \mathrm{C}$, likely due to volatilization of chromium oxide in higher temperature in air. It is well known that under oxidizing conditions at high temperature, the gaseous chromium oxides are easily produced, which hold back sintering of $\mathrm{La}_{0.8} \mathrm{Ca}_{0.2} \mathrm{CrO}_{3}$ and lead to small holes on the microstructure, which is moreover likely to impair transport of electronic carriers of the materials.

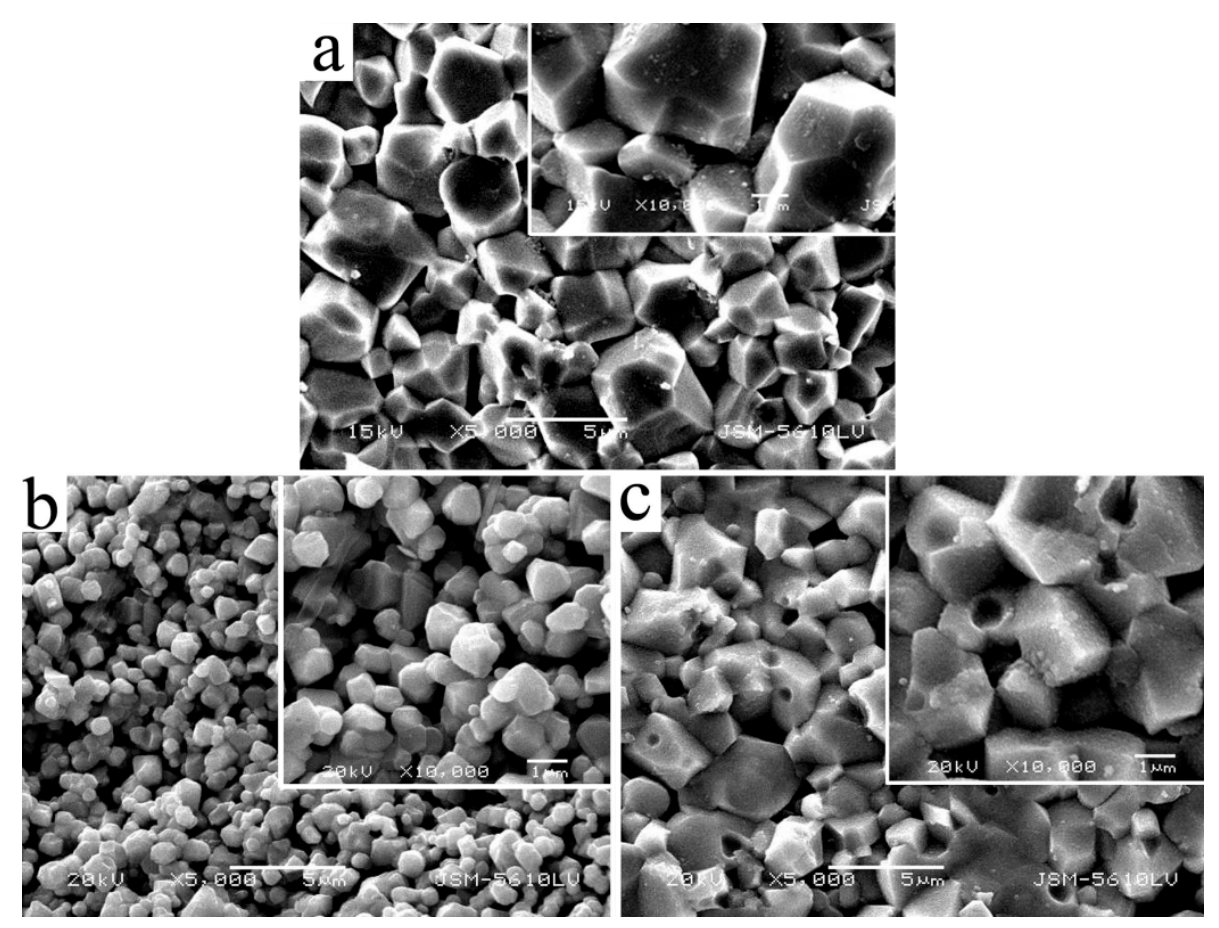

Figure 3. SEM micrographs of fracture surfaces of $\mathrm{La}_{0.8} \mathrm{Ca}_{0.2} \mathrm{CrO}_{3}$ ceramics. (a) Sintered at $1400{ }^{\circ} \mathrm{C}$ and by the combustion method; (b) sintered at $1400{ }^{\circ} \mathrm{C}$ and by the high temperature SSR method; (c) sintered at $1500{ }^{\circ} \mathrm{C}$ and by the high temperature SSR method.

Compared with that synthesized by the SSR method, the combustion method exhibited good sinterability and markedly lowered the temperature to densify $\mathrm{La}_{0.8} \mathrm{Ca}_{0.2} \mathrm{CrO}_{3}$, due to finer particle morphology and higher sintering activity. Furthermore, the decrease of sintering temperature optimized the microstructure of the ceramic and would improve physical properties.

\subsection{Electrical Transport}

Figure 4 shows the plots of $\ln \sigma_{e} T$ versus $1000 / T$ for $\mathrm{La}_{0.8} \mathrm{Ca}_{0.2} \mathrm{CrO}_{3}$ ceramics synthesized by the different methods (where $\sigma_{e}$ is the electrical conductivity and $\mathrm{T}$ is the absolute temperature). The relative densities of the two specimens were generally the same, an adequate density value of about $93 \%$. It was found that $\mathrm{La}_{0.8} \mathrm{Ca}_{0.2} \mathrm{CrO}_{3}$ synthesized by the combustion method displayed a higher electrical conductivity of $31.6 \mathrm{~S} \cdot \mathrm{cm}^{-1}$ at $800{ }^{\circ} \mathrm{C}$, while only $11.33 \mathrm{~S} \cdot \mathrm{cm}^{-1}$ for that by the SSR method. In addition, although the two specimen curves are not very linear, they are very close to linear, which indicates that small polaron-hopping is the main mechanism of conductivity behavior, as shown in the following equation $[18,19]$ :

$$
\sigma_{e}=\left(\frac{C}{T}\right) \exp \left(E_{a} / K T\right)
$$


where $C$ is a material constant containing the carrier concentration term, $T$ is the absolute temperature, $E_{a}$ is the activation energy for small polaron-hopping and $K$ is the Boltzmann constant. Moreover, the activation energies of small polarons hopping were calculated from the linear fit of the plots, $0.136 \mathrm{eV}$ for the combustion method while $0.172 \mathrm{eV}$ for the SSR methods samples. However, the difference in energy activation is not very large, a significant difference in conductivity can be observed.

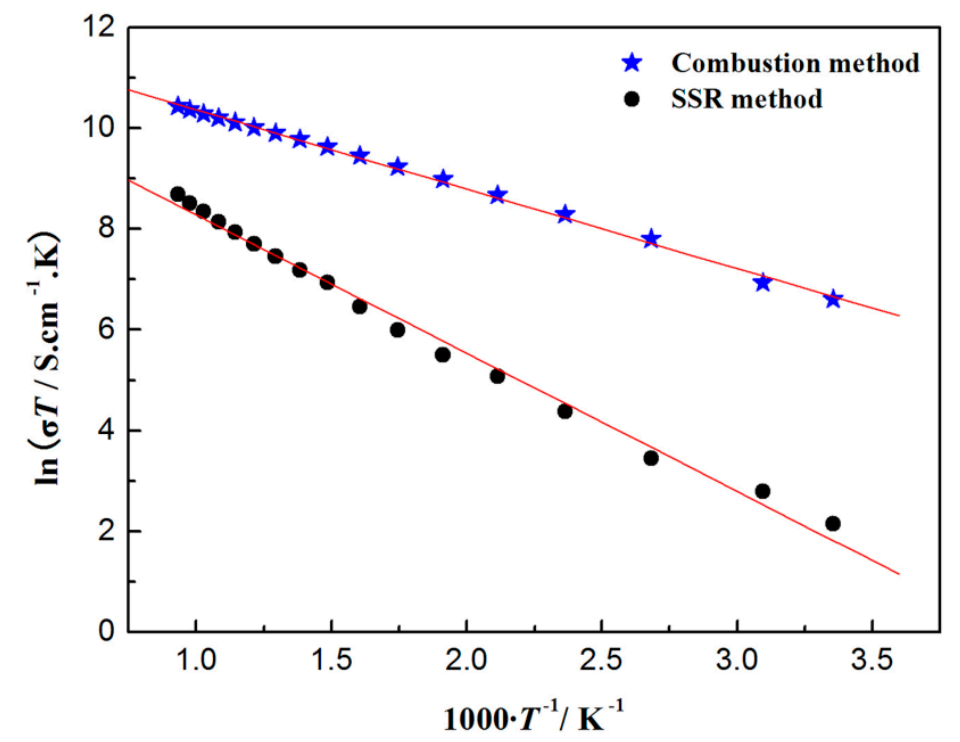

Figure 4. Plots of $\ln \left(\sigma_{e} T\right)$ versus $1000 / T$ for $\mathrm{La}_{0.8} \mathrm{Ca}_{0.2} \mathrm{CrO}_{3}$ ceramics synthesized by the different methods.

The excellent conductivity for the combustion method sample is probably related to its microstructure. The grain growth appeared perfectly straight along the boundary, and a clear grain boundary was observed (Figure 3a). However, in examining Figure $3 c$ - in addition to several holes on the surface of ceramics grains - the grains size of ceramics prepared by high temperature solid state method is obviously smaller. It shows that there are more discontinuous grain boundaries in ceramics. Generally speaking, the electronic conduction of the lanthanum chromates is essentially a bulk electronic transport property. Grain boundaries and holes can be considered as inhomogeneous components in ceramics, which hinder the transport of electron carriers. As a result, it is considered that the microstructure of the ceramics prepared by combustion method is the main reason for its excellent conductivity

On the grain surfaces of the ceramic, it can be found that the grain sizes of the ceramic prepared by the SSR method are obviously smaller, implying the existence of more grain boundaries in this material. In general, the electronic conduction of $\mathrm{La}_{0.8} \mathrm{Ca}_{0.2} \mathrm{CrO}_{3}$ is essentially a kind of bulk electrical transport property. The grain boundaries and holes can be regarded as heterogeneous components in the ceramic bulk, which block the transport of electronic carriers. Therefore, the desired microstructure of the ceramic made by the combustion method is mainly assumed to be responsible for its superior electronic conducting properties.

\subsection{Thermal Expansion}

Figure 5 shows the thermal expansion behavior of $\mathrm{La}_{0.8} \mathrm{Ca}_{0.2} \mathrm{CrO}_{3}$ ceramics synthesized by the two methods. The relative densities are approximately $93 \%$. It can be seen that-under the same density level conditions-the relative expansion $(\Delta \mathrm{L} / \mathrm{L})$ of the ceramic synthesized by the combustion method was evidently higher compared with that of the specimen by the SSR method. It is likely attributed to the different microstructures for the two methods. As inhomogeneous components in the ceramic bulk, perhaps the more grain boundaries and holes would reduce the relative expansion of the materials. Another possible mechanism may be the compositional difference because of volatilization of chromium oxide. In order to achieve the sufficient density of the perovskites, a higher sintering temperature $\left(\geq 1500^{\circ} \mathrm{C}\right)$ would be required for the SSR method. The higher sintering temperature 
results in volatilization of chromium oxide and the formation of more quadrivalent chromium ions in the perovskites structure (as for the ionic radii, $\mathrm{Cr}^{4+}=0.069 \mathrm{~nm}, \mathrm{Cr}^{3+}=0.0755 \mathrm{~nm}$ ) [20], and lower the TEC of the sample synthesized by SSR method.

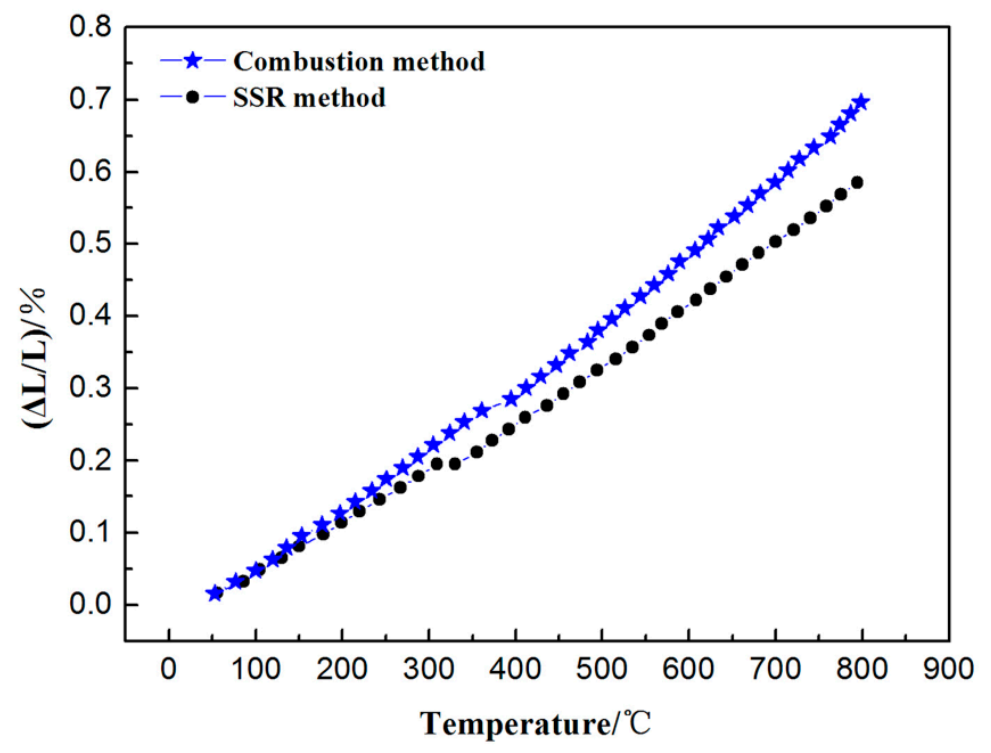

Figure 5. Thermal expansion behaviors of $\mathrm{La}_{0.8} \mathrm{Ca}_{0.2} \mathrm{CrO}_{3}$ ceramics synthesized by the different methods.

In addition, there is a kink in the measuring temperature range from $300{ }^{\circ} \mathrm{C}$ to $400{ }^{\circ} \mathrm{C}$, which may be owing to the orthorhombic to rhombic phase-transition, in agreement with Sakai et al. [21] and Hayashi et al. [22], and confirmed by Gupta et al. [23] using the DSC and high temperature XRD results. The thermal expansion coefficients (TECs) of the two samples prepared by different methods were $10.5 \times 10^{-6} \mathrm{~K}^{-1}$ and $9.6 \times 10^{-6} \mathrm{~K}^{-1}$ in high temperature, respectively. Obviously, the former was thermally compatible with that of other high-temperature components for use in SOFC, such as $8 \mathrm{YSZ}$ electrolyte $\left(10.5 \times 10^{-6} \mathrm{~K}^{-1}\right)$, so as to minimize thermal stresses. All the above results demonstrated that the discrepancies in the electrical conductivity and TEC corresponded well to the microstructural variations of the ceramics, due to the different sinterability of $\mathrm{La}_{0.8} \mathrm{Ca}_{0.2} \mathrm{CrO}_{3}$ synthesized by the two methods. By contrast, the specimen by the combustion method exhibits lower densified temperature and better physical properties. Present research work provided new clue for the synthesis of new composites and nanomaterials [24-29].

\section{Conclusions}

In summary, the sinterability, electrical transport and thermal expansion of $\mathrm{La}_{0.8} \mathrm{Ca}_{0.2} \mathrm{CrO}_{3}$ synthesized by the combustion method were studied and compared with that of synthesized by the high temperature SSR method. It was found that the combustion method could effectively enhance the sinterability of $\mathrm{La}_{0.8} \mathrm{Ca}_{0.2} \mathrm{CrO}_{3}$ ceramic and reduce the sintering temperature of the materials because of higher sintering active powders. Moreover, lower sintering temperature optimized the microstructure of the ceramic and would elevate the electrical conductivity and TEC. The combustion method was proved to be a favorable synthesis process for $\mathrm{La}_{0.8} \mathrm{Ca}_{0.2} \mathrm{CrO}_{3}$ complex oxides.

Author Contributions: M.J. and T.J. conceived and designed the experiments; L.L. and J.Y. performed the experiments; W.G. and T.J. analyzed the data; M.J. and W.G. contributed reagents/materials/analysis tools; L.L., M.J. and T.J. wrote and revised the paper. All authors have read and agreed to the published version of the manuscript.

Funding: This research was funded by the National Natural Science Foundation of China (no. 21872119).

Conflicts of Interest: The authors declare no conflicts of interest. 


\section{References}

1. Feduska, W.; Isenberg, A.O. High-temperature solid oxide fuel cell-technical status. J. Power Sources 1983, 10, 89-102. [CrossRef]

2. Minh, N. Ceramic Fuel Cells. J. Am. Ceram. Soc. 1993, 76, 563-588. [CrossRef]

3. Zhu, W.Z.; Deevi, S.C. Development of interconnect materials for solid oxide fuel cells. Mater. Sci. Eng. A 2003, 348, 227-243. [CrossRef]

4. Zhou, X.L.; Ma, J.; Deng, F.; Meng, G.Y.; Liu, X.Q. A high performance interconnecting ceramics for solid oxide fuel cells (SOFCs). Solid State Ionics 2007, 177, 3461-3466. [CrossRef]

5. Singhal, S.C.; Kendall, K. (Eds.) High-Temperature Solid Oxide Fuel Cells: Fundamentals, Design and Applications; Elsevier: Amsterdam, The Netherlands, 2003. [CrossRef]

6. Fergus, J. Lanthanum chromite-based materials for solid oxide fuel cell interconnects. Solid State Ionics 2004, 171, 1-15. [CrossRef]

7. Groupp, L.; Adersen, H.U. Densification of $\mathrm{La}_{1-x} \mathrm{Sr}_{\mathrm{x}} \mathrm{CrO}_{3}$. J. Am. Ceram. Soc. 1976, 59, 449-450. [CrossRef]

8. Yokokawa, H.; Sakai, N.; Kawada, T.; Dokiya, M. Thermodynamic analysis of reaction profiles between $\mathrm{LaMO}_{3}(\mathrm{M}=\mathrm{Ni}, \mathrm{Co}, \mathrm{Mn})$ and $\mathrm{ZrO}_{2}$. J. Electrochem. Soc. 1991, 138, 2719-2726. [CrossRef]

9. Mori, M.; Yamamoto, T.; Ichcikawa, T.; Takeda, Y. Dense sintered conditions and sintering mechanisms for alkaline earth metal $(\mathrm{Mg}, \mathrm{Ca}$ and $\mathrm{Sr})$-doped $\mathrm{LaCrO}_{3}$ perovskites under reducing atmosphere. Solid State Ionics 2002, 148, 93-101. [CrossRef]

10. Chick, L.; Liu, J.; Stevenson, J.; Armstrong, T.R.; McCready, D.E.; Maupin, G.D.; Coffey, G.W.; Coyle, C.A. Phase Transitions and Transient Liquid-Phase Sintering in Calcium-Substituted Lanthanum Chromite. J. Am. Ceram. Soc. 1997, 80, 2109-2120. [CrossRef]

11. Kallarackel, T.; Gupta, S.; Singh, P. Thermodynamic Properties of $\mathrm{LaCrO}_{4}, \mathrm{La}_{2} \mathrm{CrO}_{6}$, and $\mathrm{La}_{2} \mathrm{Cr}_{3} \mathrm{O}_{12}$, and Subsolidus Phase Relations in the System Lanthanum-Chromium-Oxygen. J. Am. Ceram. Soc. 2013, 96, 3939-3948. [CrossRef]

12. Stevenson, J.W.; Hallman, P.F.; Armstrong, T.R.; Chick, L.A. Sintering Behavior of Doped Lanthanum and Yttrium Manganite. J. Am. Ceram. Soc. 1995, 78, 507-512. [CrossRef]

13. Yasuda, I.; Hikita, T. Formation of calcium chromate hydroxylapatite on the surface of a calcium-doped lanthanum chromite sintered body. J. Mater. Sci. 1994, 29, 2801-2805. [CrossRef]

14. Masashi, M.; Yoshiko, H.; Nigel, M.S. Sintering behavior and mechanism of Sr-doped lanthanum chromites with a site excess composition in air. Solid State Ionics 1999, 123, 103-111.

15. Guo, W.; Wang, Y.; Li, A.; Jiao, T.; Gao, F. Effect of sintering temperature on microstructure, electrical properties, and thermal expansion of perovskite-type $\mathrm{La}_{0.8} \mathrm{Ca}_{0.2} \mathrm{CrO}_{3}$ complex oxides synthesized by a combustion method. J. Electron. Mater. 2013, 42, 939-943. [CrossRef]

16. Guo, W.; Xu, Q.; Huang, D.; Jiao, T.; Gao, F. Investigation on the calcining condition and sintering temperature of perovskite-type $\mathrm{La}_{0.7} \mathrm{Ca}_{0.3} \mathrm{CrO}_{3}$ complex oxides by a combustion method. Mater. Res. Bull. 2012, 47, 2067-2071. [CrossRef]

17. Chick, L.; Pederson, L.; Maupin, G.; Maupin, J.; Bates, L.; Thomas, G. Glycine-Nitrate Combustion Synthesis of Oxide Ceramic Powder. Mater. Lett. 1990, 10, 6-12. [CrossRef]

18. Armstrong, T.R.; Stevenson, J.W.; Hansinska, K.; McCready, D.E. Synthesis and Properties of Mixed Lanthanide Chromite Perovskites. J. Electrochem. Soc. 1998, 145, 4282-4289. [CrossRef]

19. Xiong, H.; Zhang, G.J.; Zheng, J.Y. Synthesis, crystal structure and electric conductivity of $\mathrm{La}_{0.9} \mathrm{Ca}_{0.1} \mathrm{Cr}_{0.5} \mathrm{~B}_{0.5} \mathrm{O}_{3}$ (B = Mn, Fe, Ni). Mater. Lett. 2001, 51, 61-67. [CrossRef]

20. Mori, M.; Hiei, Y.; Yamamoto, T. Thermal Expansion Control Technique of Sr-Doped Lanthanum Chromite Perovskites by B-Site Doping for High-Temperature Solid Oxide Fuel Cell Separators. J. Am. Ceram. Soc. 2001, 84, 781-786. [CrossRef]

21. Sakai, N.N.; Stolen, S. Heat capacity and thermodynamic properties of lanthanum(III) chromate(III): $\mathrm{LaCrO}_{3}$, at temperatures from $298.15 \mathrm{~K}$. Evaluation of the thermal conductivity. J. Chem. Thermodyn. 1995, 27, 493-506. [CrossRef]

22. Hayashi, H.; Watanabe, M.; Inaba, H. Measurement of Thermal Expansion Coefficient of $\mathrm{LaCrO}_{3}$. Thermochim. Acta 2000, 359, 77-85. [CrossRef]

23. Gupta, S.; Mahapatra, M.; Singh, P. Phase transformation, thermal expansion and electrical conductivity of lanthanum chromite. Mater. Res. Bull. 2013, 48, 3262-3267. [CrossRef] 
24. Ge, L.; Zhang, M.; Wang, R.; Li, N.; Zhang, L.; Liu, S.; Jiao, T. Fabrication of CS/GA/RGO/Pd composite hydrogels for highly efficient catalytic reduction of organic pollutants. RSC Adv. 2020, 10, 15091-15097. [CrossRef]

25. Wang, R.; Yan, X.; Ge, B.; Zhou, J.; Wang, M.; Zhang, L.; Jiao, T. Facile preparation of self-assembled black phosphorus-dye composite films for chemical gas sensors and surface-enhanced Raman scattering performances. ACS Sustain. Chem. Eng. 2020, 8, 4521-4536. [CrossRef]

26. Feng, Y.; Yin, J.; Liu, S.; Wang, Y.; Li, B.; Jiao, T. Facile synthesis of Ag/Pd nanoparticles-loaded polyethyleneimine composite hydrogels with highly efficient catalytic reduction of 4-nitrophenol. ACS Omega 2020, 5, 3725-3733. [CrossRef]

27. Zhang, L.; Yin, J.; Wei, K.; Li, B.; Jiao, T.; Chen, Y.; Zhou, J.; Peng, Q. Fabrication of hierarchical SrTiO3@MoS2 heterostructure nanofibers as efficient and low-cost electrocatalyst for hydrogen evolution reaction. Nanotechnology 2020, 31, 205604. [CrossRef] [PubMed]

28. Yang, M.; Liu, R.; Chen, H.; Li, H.; Guo, P. Synthesis of self-assembled nickel cobaltite microspheres and their electrocapacitive behavior in aqueous electrolytes. Colloid Surf. A 2020, 587, 124329. [CrossRef]

29. Sun, J.; Yang, M.; Gong, Y.; Li, H.; Guo, P. Synthesis of Pd3Pb colloidal nanocrystal assembly and their electrocatalytic activity toward ethanol oxidation. Colloid Surf. A 2020, 586, 124224. [CrossRef]

(C) 2020 by the authors. Licensee MDPI, Basel, Switzerland. This article is an open access article distributed under the terms and conditions of the Creative Commons Attribution (CC BY) license (http://creativecommons.org/licenses/by/4.0/). 